\title{
Reversal Theory from a Design Perspective
}

\author{
Steven Fokkinga and Pieter Desmet \\ Delft University of Technology
}

\begin{abstract}
Designers increasingly make use of psychological theory to understand a product's user and to support their design efforts. This paper considers how insights from reversal theory have informed and inspired design research and practice. We identify two key benefits of reversal theory over other theories: it offers a dynamic rather than static, and a holistic rather than fragmented model of human functioning. Based on different aspects of reversal theory, six design opportunities were formulated: Products that are inspired by motivational states, products that make use of users' motivational states, products that reverse motivational states, products that provide a variety of experience through psychodiversity, products that communicate and surprise through cognitive synergies, and products that offer emotionally rich experiences through parapathic emotions. Each of these opportunities is illustrated with examples of existing products and conceptual design.
\end{abstract}

Keywords: product design, reversal theory, metamotivational states, parapathic emotions, cognitive synergy

\section{Introduction}

While reading this paper you may sit on a chair, wear glasses, and perhaps you have a pen in your hand and a phone in your pocket - these represent but a few examples of the numerous products that people use in their everyday lives: cars, kitchen appliances, office tools, computers, phones, sports equipment, and so on. All these products have been designed by industrial designers. Originated during the industrial revolution, and matured in the age of industrialization, the industrial design profession has been responsible for conceptualizing products that are produced on an industrial scale and for optimizing these products in terms of function, value, and appearance for the mutual benefit of user and manufacturer (Heskett, 1980). The discipline is analytic, creative, and essentially integrative: designers combine knowledge from various domains, such as usability, ergonomics, emotion psychology, engineering, marketing, and aesthetics. The process of conceptualizing and materializing designs always involves

Steven Fokkinga, Department of Industrial Design, Delft University of Technology; Pieter Desmet, Department of Industrial Design, Delft University of Technology.

Picture Acknowledgments. All images are reprinted with permission. The authors wish to thank the individuals and institutions who kindly provided photographic materials for use in this manuscript.

Correspondence concerning this article should be addressed to Steven Fokkinga, Delft University of Technology, Department of Industrial Design, Landbergstraat 15, 2628 CE Delft, The Netherlands E-mail: s.f.fokkinga@tudelft.nl a high level of uncertainty because it operates with indefinite and incomplete criteria for the intended end-result. Designers create products for a variety of user groups, like children in wheelchairs, police officers, truck drivers, school teachers, and so on. In most cases, the designer does not belong to the user group, nor does she have first-hand experience or direct access to users and usage situations. To deal with this uncertainty in design processes, industrial designers use methodologies to structure their creative and analytical activities (for an overview, see Van Boeijen, Daalhuizen, Zijlstra, \& Van Der Schoor, 2013). They use research methods, such as observation and interviews to understand the problems, needs, and desires of the users (e.g., Visser, Stappers, Van der Lugt, \& Sanders, 2005) and design methods such as co-design to involve the users in the design process (e.g., Sanders \& Stappers, 2008).

In addition to investing time and effort in analyzing the user group, designers also use knowledge drawn from social sciences to help them understanding their intended users. For example, when designing for people with diabetes, designers use knowledge about diabetes and about its social and psychological effects. Besides such domain-specific or applied knowledge, designers are also inspired by general theory that provides basic principles of human behavior, functioning, and experience. General principles are popular in the design discipline because they offer dimensions that designers can use to typify the user group they are designing for. Examples of often-used theories are typologies of needs and goal, like Ford's (1992) goal typology, Maslow's (1943) hierarchal need structure, and the need typology by Sheldon and his colleagues (2001), all of which include lists and structures of universal needs, such as safety, autonomy, related- 
ness, and competence. Also popular are dimensional models about personality and culture, such as the five-factor personality model of Digman (1990) and Hofstede's (2005) model of cultural dimensions.

The advantage of these and similar structures is that, by reducing the complexity of human nature to a set of manageable dimensions, they provide an efficient and effective means for developing a focused user profile. This profile can be used to develop personas (Miaskiewicz \& Kozar, 2011) or to serve as the basis for further investigation into the user's needs and desires (e.g., Ozkaramanli, Fokkinga, Desmet, Balkan, \& George, 2013). The disadvantage is that reducing complexity inherently involves a risk of generating blind spots for nuances that are relevant for the particular and specific context of design. For example, most emotion typologies only include two or three positive emotions while designers require a more nuanced differentiation of user experience (Desmet, 2012). Moreover, the models and typologies used by designers mostly favor a static approach to describing human nature. This may stimulate designers to wrongfully assume that their users are static - ignoring the dynamics of human nature and the related paradoxical needs and desires. Another pitfall of often-used models and typologies in design is that most of them focus on only one aspect of human functioning - for example, on personality (e.g., Digman, 1990), emotional experience (e.g., the PAD model; Mehrabian, 1995), or universal human values (e.g., Schwartz, 1994). While each of these theories can be insightful in relation to the aspect it addresses, it can also create an incomplete or scattered view on the user, making it difficult for designers to integrate insights into a holistic understanding.

In this paper, we propose that reversal theory can contribute to design in two important ways. The first contribution is that it offers a dynamic model of human functioning. Whereas designers can tend to develop a static model of the user (i.e. defining their needs, their preferred experiences, their problems, and their personalities), reversal theory offers possibilities for generating user profiles that are richer and more accurate. One of reversal theory's main propositions is that people's wants and needs are not governed by static personality traits, but rather constantly changing. ${ }^{1}$ Moreover, it proposes that there is a structure underlying this dynamic process, with pairs of opposing motivational states, see Figure 1.

The second contribution is that reversal theory offers a perspective on human functioning that is more holistic than the theories that are currently popular in design. This allows a more inclusive and precise understanding of what users want, feel and do. The holistic nature of the theory emerges in its explicit link between what people want (motivation), feel (emotional experience), and do (behavior): it proposes that the latter two depend on and originate from the first: the

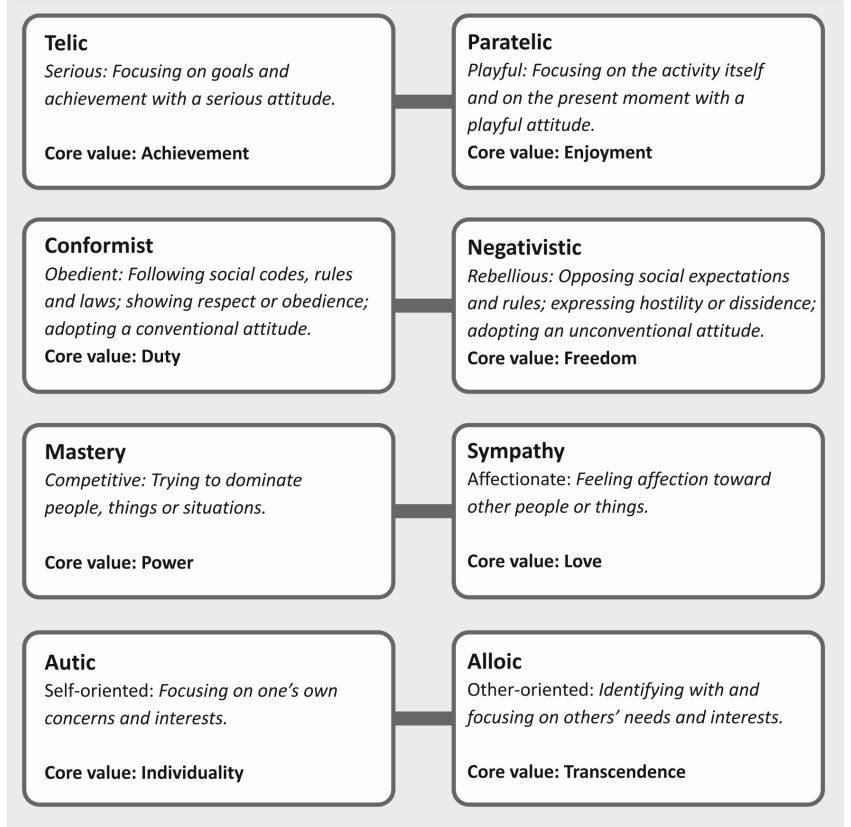

Figure 1. Illustration of the four motivational state pairs. Every individual is always on one side in each of the four above shown motivational state pairs, which determines his or her momentary motivations. Each state is anchored in core value and a motivational style. For example, a person in the telic state is actively achieving goals, wants to minimize problems and detours, and dislikes high arousal. A person in the paratelic state, on the other hand, is actually looking to increase arousal and stimulation, and sees problems as challenges (after Apter, 2007b, p. 227; descriptions drawn from Mullet, Kpanake, Zounon, Guedj, \& Sastre, 2014).

motivational state that the user is currently in. Knowing the current motivational state of an individual and a given stimulus or event, explanations and predictions can be made about the resulting emotional experience and behavior of the individual. By showing an explicit relationship between these three human aspects, which are arguably the most important in user-centered design, the theory provides designers with a more inclusive and integrated understanding of the user.

While acknowledging these contributions, it should be noted that an important reason that certain theories are popular in the design community is their propensity to be understood and applied without requiring significant time invest-

\footnotetext{
${ }^{1}$ There are three main ways in which motivations reverse to the opposite state: Contingency, frustration, and satiation. Contingency represents a change in the environment, which also includes events encountered in human-product interaction. The second occurs when the goals in that state have been sufficiently frustrated. Satiation occurs when the person has spent a certain amount of time in a given state. (Apter, 2007)
} 

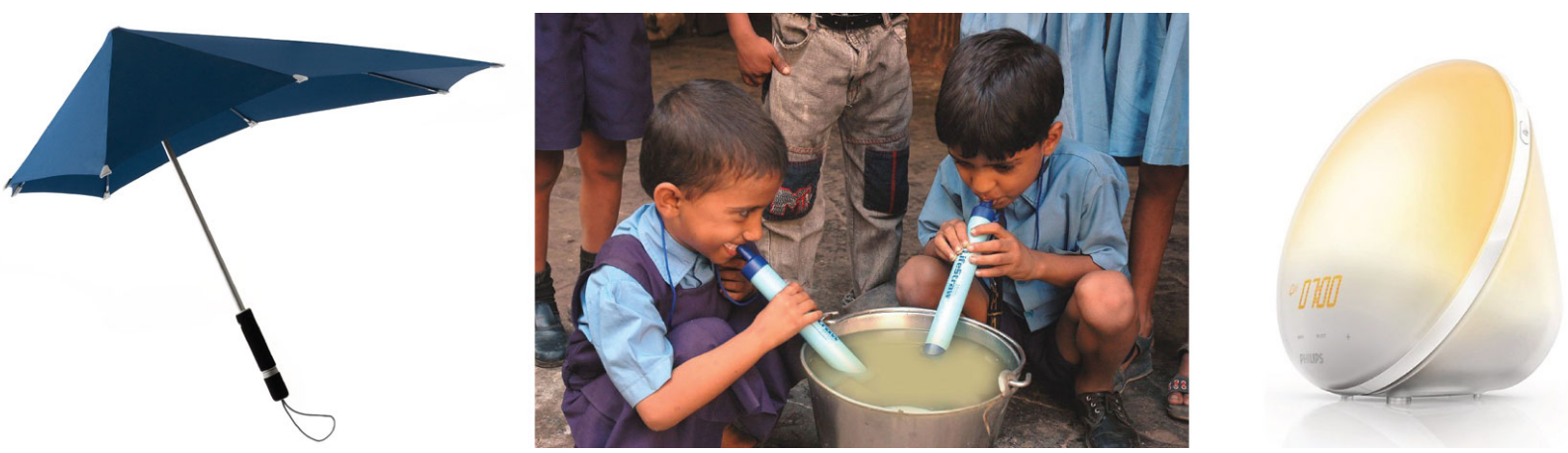

Figure 2. Three typical examples of industrial designs - Senz Umbrella, Life Straw by Vestergaard, Philips Wake-Up Light

ment. In other words, while representing complex insights, the models and typologies are, in themselves, easy to understand and apply. This may explain, for example, why many design students still favor Maslow's classic need structure, even though more recent and nuanced need theory is available. Because reversal theory offers many insights that are relevant to designers, but also needs some effort to be properly understood, we propose that it can be fruitful to offer some help to designers. For that reason, the purpose of this paper is to provide a pragmatic analysis of reversal theory for application in the design discipline. Without claiming completeness, we identified six design opportunities that are inspired and facilitated by reversal theory. Each insight is shortly explained and illustrated with the use of design examples. The discussion section reflects on the insights and the implications for both design and reversal theory.

\section{Six Design Opportunities}

Industrial design is generally described as a "problemsolving" activity (Roozenburg \& Eekels, 1995): an activity that creates solutions to remove or minimize a problem - an identified discrepancy between the current and a desired state. In practical terms, products make things easier, cleaner, cheaper, safer, more comfortable, and so on. In line with this view, the relevance of products - their purpose - can be explained in terms of the problems they solve. Figure 2 shows some examples.

The purpose of the stormproof Senz Umbrella (Senz, n.d.) is to protect users against rain in winds of up to 70 miles per hour. The three design students who developed this umbrella were motivated by their frustration with the inability of conventional umbrellas to withstand wind. The purpose of the Life Straw portable filter (Vestergaard, n.d.) is to remove bacteria and parasites from contaminated water sources directly while drinking. The underlying problem is that people face serious health risks if they do not have access to clean and safe drinking water. The purpose of the Wake-Up Light (Philips, n.d.) is to awaken users with light that imitates a natural sunrise. The underlying problem that it aims to solve is that people who use conventional alarm clocks can suffer from a lack of energy during the day because they wake up unnaturally.

Someone who takes a reversal theory perspective could conclude that problem-solving design is relevant and functional for only one of the eight motivational states: the telic (serious) state in which people are motivated by achieving goals and minimizing arousal or stress in the process of achieving these goals (see Figure 1). Obviously, people use products like the Life Straw, the Senz Umbrella and the Wake-Up Light as tools to reach their goals or to minimize stress, discomfort, or effort in the process of reaching their goals. The proposition brought forward in this paper, however, is that everyday products play meaningful roles in all of the eight states. To illustrate this idea, Figure 3 shows an example of how driving a car can facilitate experiences for each of the eight motivational states.

The suggestion that products play meaningful roles in all motivational states implies that designers can understand their intended users in terms of a combination of a functional goal and a motivations state, rather than only in terms of a functional goal. The six design opportunities discussed in this paper aim to explore the resulting new design space. They are introduced in two parts. In part A, four opportunities are discussed that are inspired and informed by an understanding of the different motivational states that underlie people's behavior and experience with products. In part B, we highlight two additional opportunities that have a specific focus on the paratelic (playful) state: cognitive synergies (two opposing mental concepts) and parapathic emotions (positive variants of negative emotions):

A: 1) Products that are inspired by motivational states

2) Products that make use of users' motivational states

3) Products that reverse motivational states

4) Products that provide variety of experience through psychodiversity

B: 5) Products that communicate and surprise through cognitive synergies 


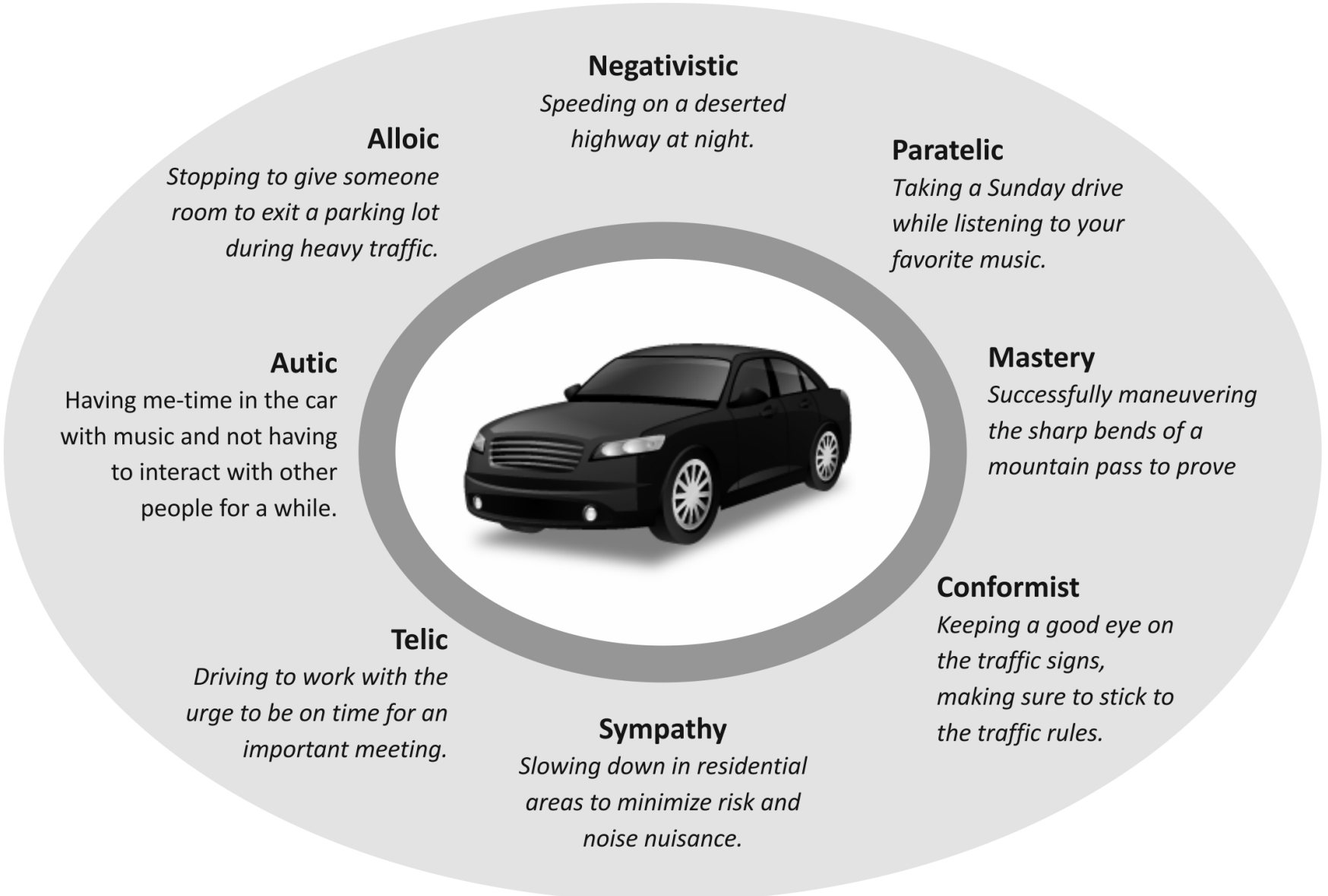

Figure 3. A car can support each of the eight states

6) Products that offer emotionally rich experiences through parapathic emotions

The following sections introduce each opportunity and provide design examples to illustrate application possibilities. $^{2}$

\section{A: Focus on Opportunities Informed by Metamotiva- tional States}

Design opportunity 1: Products that are inspired by motivational states. The eight motivational states can be used as a basic source of inspiration to create a diverse pallet of user experiences for a given product functionality. For example, when designing a teacup, the designer can focus on the telic state and aim to design a cup that is as efficient and safe as possible, or on the paratelic state and aim to design a cup that stimulates a playful tea-drinking experience. Because each of the other states can be taken as a source of inspiration, this diversity can support the creative thinking process. For example, imagine what a teacup would look like that is optimized for a negativistic or an alloic state. Figure
4 provides some illustrative examples for each of the four motivational state pairs.

While fulfilling the purpose of drawing, a pen can facilitate a telic (professional drawing pen in (4a)) or a paratelic experience (rainbow colored pencils in (4b)). The professional pen enables precise drawing and is optimized in terms of efficiency and usage comfort. The rainbow colored pencil is characterized by a lack of control because the color changes randomly during use. While fulfilling the purpose of "personal transport," a car can facilitate a conformist (electric car in (4c)) or a negativistic experience (Hummer in (4d)). An electric car represents social values and norms, such as sustainability and modesty, whereas a hummer 'rebels'

\footnotetext{
${ }^{2}$ Note that the design examples in this paper illustrate how principles of reversal theory could be used in design processes. In most cases, these designs have been developed with the use of principles that were drawn from additional or other theories. For example, the Morning Tapas breakfast in Figure 6 was developed with the use of appraisal theory from cognitive emotion psychology. Those who are interested in these design cases are referred to the original sources.
} 

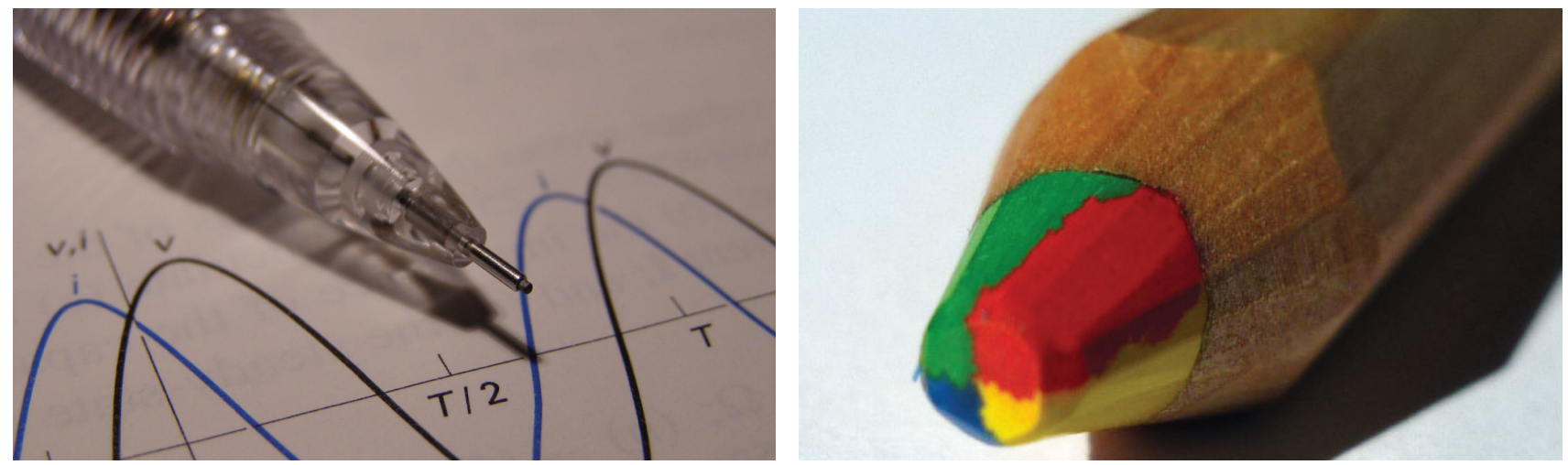

(a)

(b)
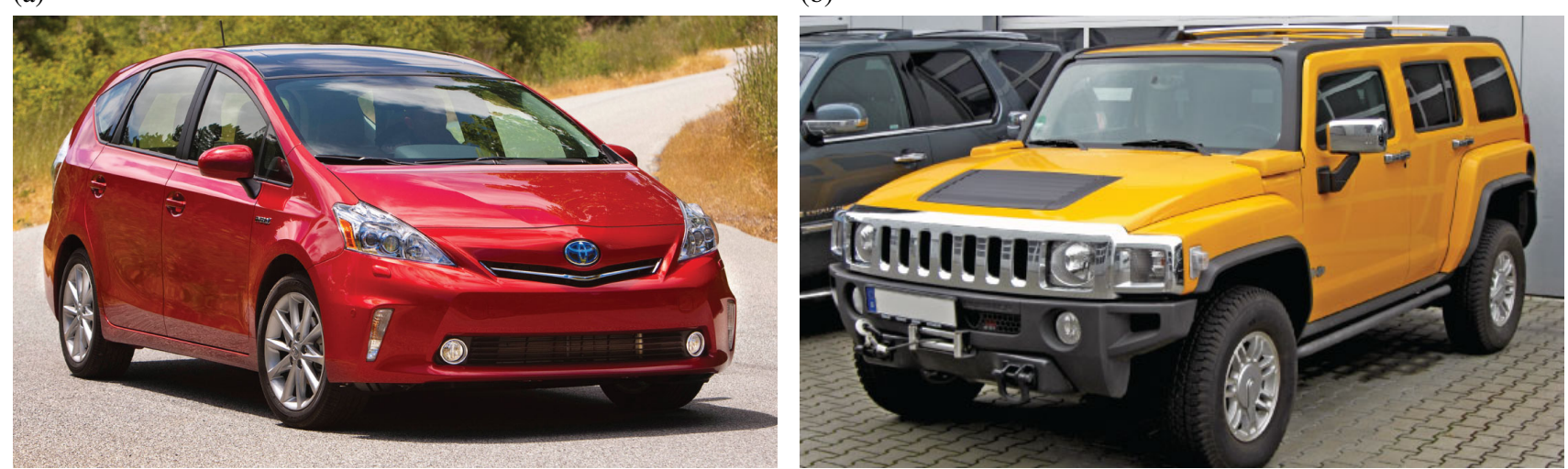

(c)

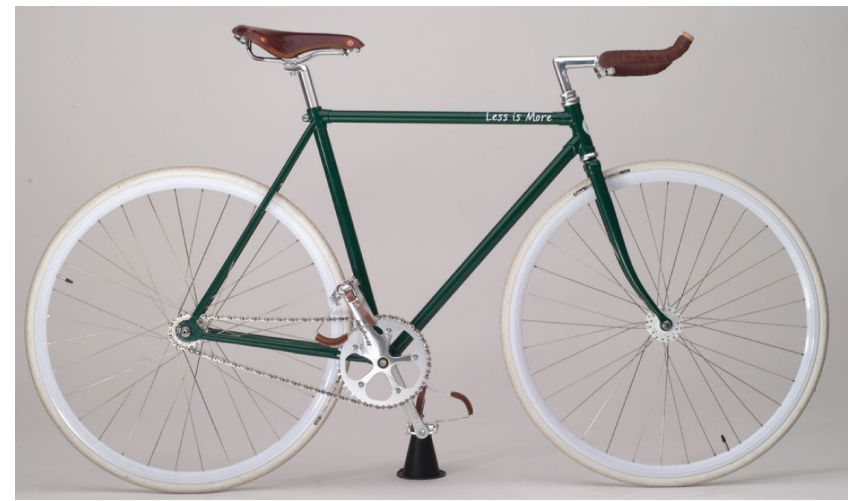

(e)

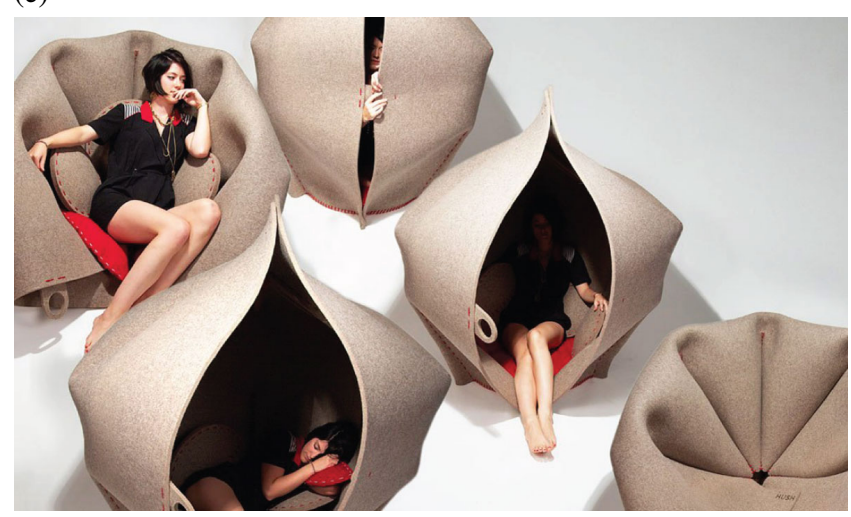

(g) (d)

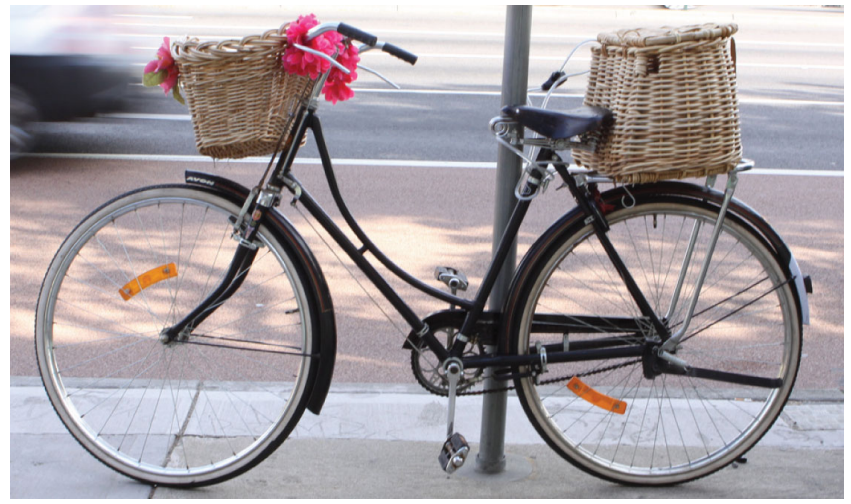

(f)

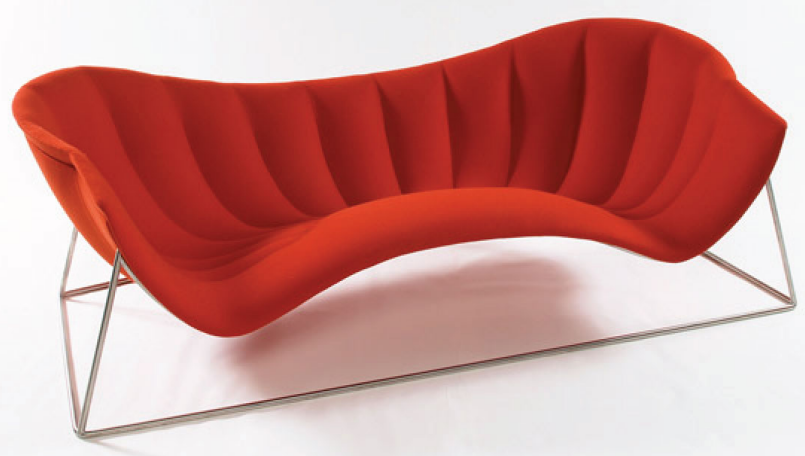

(h)

Figure 4. Examples of design that support motivational states 
against these same values by being unsustainable and by discouraging a mannerly driving style. A bicycle can facilitate a mastery ('fixie-bike' in (4e)) or a sympathy experience ('grandma-bike' in (4f)). The fixie-bike lacks common features such as gears and brakes and requires much practice to master as opposed to the grandma-bike, which has a friendly expression that communicates an affectionate attitude towards pedestrians. While fulfilling the purpose of "offering physical support to the body", a chair can facilitate self-oriented (Hush Pod in (4g)) or other-oriented experiences (The 'Calypso' love seat in (4h)). The "Hush Pod" (by Freyja Sewell) is made from felt that the user can wrap around herself so she sits in a cocoon-like enclosure. This can provide an effective experience for people who want to temporarily close themselves off from the rest of the world. Conversely, the Calypso love seat (by Jon Goulder) enables people to sit together comfortably and in a subtle way encourages them to face each other.

These examples illustrate that products can be designed with different motivational states in mind. Taking this into consideration can help designers to create products that differ from those already available in a way that is meaningful and attractive to users. It can even stimulate creative functionalities by focusing on motivational states that are unexpected or counter-intuitive for the given product purpose. For example, "Charity Miles" is a smartphone app for runners that donates $25 \mathbb{c}$ for every mile they run to a charity of their choice ("Charity Miles," n.d.). By involving the virtue of generosity in the experience, runners can experience the other-oriented state while doing something that is also good for themselves.

The most straightforward application of this design opportunity is to focus on single motivational states. Nuance can be added by focusing on combinations of states. The easy-rider bicycle, for example, can be seen as an expression of both an affectionate and a playful state. Similarly, the Hummer is not only an expression of a negativistic state, but also of a self-oriented state. An interesting design challenge would be, for example, to redesign the Hummer with the intention to support an other-oriented state, while maintaining the rebellious experience. Focusing on combinations rather than on single states opens up a richer and more nuanced design space. In addition, it can be interesting to design for some flexibility that enables the user to determine which state to support. The Hush Pod chair can be considered an expression of this approach: Although it predominantly facilitates a self-oriented state, the user can also remodel the chair to facilitate a more other-oriented state.

Design opportunity 2: Products that make use of users' motivational states. Beyond using motivational states as a basic source inspiration, designers can also use an understanding of these states to research users in specific situations ("contexts of use") and to design products and product features that take these specific states into account. The

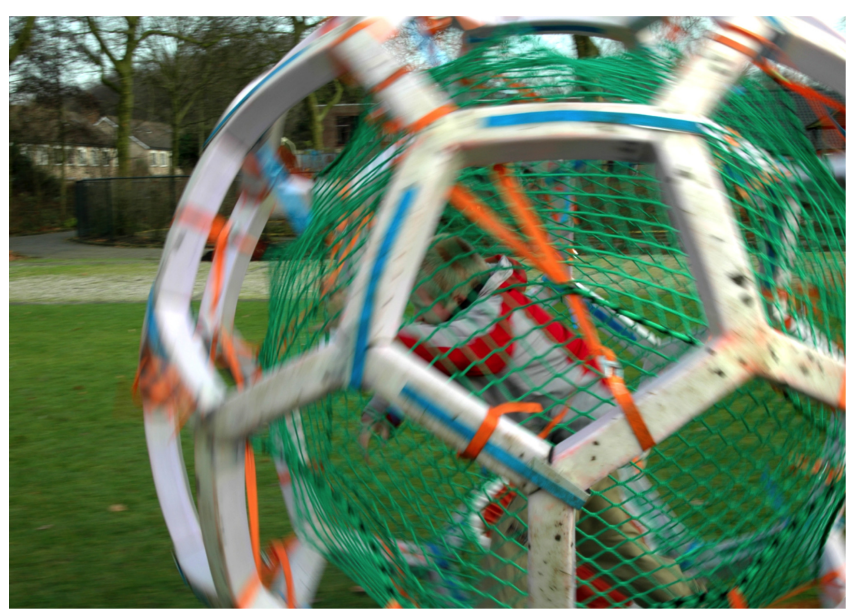

Figure 5. Link Ball - supporting rebellious behavior

Designed by Gina van der Werf. Link, a device for stimulating blind children to engage in physically active play, is a ball of $2 \mathrm{~m}$ ( $7 \mathrm{ft}$.) diameter, in which a child can stand, walk and run around, without getting hurt by the environment. The concept appeals to the notion of playing with chaos and order, while giving abundant proprioceptive feedback. Setting the ball in motion sets the child in motion, which affects the ball and so on. There is a commitment to every move the child makes. At the same time, the enclosed space is safe to fall down in, and protects the child from directly hitting something. The child is in charge of how much the ball is initially set in motion and thereby controls the level of chaos.

context of use is the social and physical environment or situation in which the product is used. This can include locations (e.g., an office; an airplane), activities (e.g., watching TV; working out), social settings (e.g., with a few strangers; with a large group of friends), occasions (e.g., a festival; a medical check-up), and so on. Each of these factors influences how products are used and experienced. It depends on the product to what extent the context of use can be determined - some products are only used in certain situations (such as fire extinguishers and balloons), while others can be used in a variety of contexts (such as mobile phones). In any case, an understanding of the possible motivational states in the context of use is key in conceptualizing new products.

This is well illustrated in the case of Link ball (see Figure 5), which is a device for stimulating blind children to engage in physically active play (for a full description of the project, see Desmet \& Schifferstein, 2011). The project investigated how blind children play outside and how their activities could be supported by design. The main challenge is to get enough exercise, while not getting hurt by running into obstacles or tripping. The designer found that there were already numerous design solutions to keep children safe in their play. Examples are special treadmills and swings that 
help children to be in the playful (paratelic) state by shielding them from dangers that would inevitably evoke the telic state in them. However, the designer's most important insight, in reversal theory terms, was that this playful (paratelic) state always came with constraints, rules and external support only allowing fun while being in the conformist state. What a lot of children craved, and could not get with existing solutions, was wild, uncontrolled fun: being in the negativisticparatelic state. The designer created Link to support this experience of uncontrolled fun. Because the ball protected the users against any obstacles, they could run chaotically across the field in a manner that sighted children also tend to enjoy. The product had a profound impact on the children - they were able to fulfill a desire some of them had never been able to fulfill before.

An understanding of the user's situation allowed the designer of the Link ball to create a product that satisfied the user's desire as its main purpose. However, an existing product can also be redesigned to support an appropriate motivational state beyond its primary function. This can be illustrated by an example of an airline breakfast that was designed to mentally stimulate people and makes them feel in control (for a full description, see Desmet \& Schifferstein, 2012). An airline company wanted to find a solution that improved people's liking of an airplane breakfast. This was the breakfast that the airline served on intercontinental flights, in the morning after passengers had spent the night in the plane. Through interviews and observations, the designers discovered that, in the context of eating breakfast in a plane, people felt stuck in a conforming state and wanted to have some freedom in their actions. In addition, they found that the breakfast moment was usually in one of the last hours of a long flight, at which point passengers had already been strapped in their chair for more than eight hours. At this point in the flight, most passengers were tired with the movies and other entertainment options that are offered through the monitors and have been sitting next to the same people for a long time. In other words, the passengers were in the paratelic state and looking for some enjoyable stimulation. Neither of these problems, lack of freedom and lack of stimulation, had to do with the primary function of the breakfast (providing sustenance) nor had passengers expressed that they expected this from the breakfast. However, the breakfast did provide an interesting vehicle to fulfilling both these needs. The solution was a new breakfast concept called "Morning Tapas" (see Figure 6). The experimentation and surprising outcomes that were afforded by the ability to personalize the meal turned the breakfast from a commodity into a source of pleasant stimulation. In this way, the design of the breakfast acknowledged that people in this specific context were primarily in the negativistic state (looking for freedom) and in the paratelic state (looking for stimulation).
The possibility of explicitly using a person's motivational state is interesting for one other objective: design for behavioral change. A recent development in design is to use products in persuading people to change their behavior, either for their personal benefit (e.g., a product that encourages the user to do physical exercise) or for social gain (e.g., design that promotes active participation in the community) (e.g., Fogg, 2009). Tromp and colleagues (2011) described how designers can employ different strategies, from coercing to seducing, to change people's behavior for the common good. For example, if a company wants its employees to take more social breaks and talk to each other, placing a shared coffee machine in the hallway is a very effective intervention. Even if people are not aware that the intended effect is social interaction, (or perhaps, especially if they are not aware), it is still likely to succeed, because they like to spend social breaks as a variation to their solitary computer work.

Reversal theory emphasizes that intended behavior always starts with subjective experience, which in turn depends on the current motivational state. This means that in order to change someone's behavior, it is important to know in what motivational state the user is (or is likely to be). This was

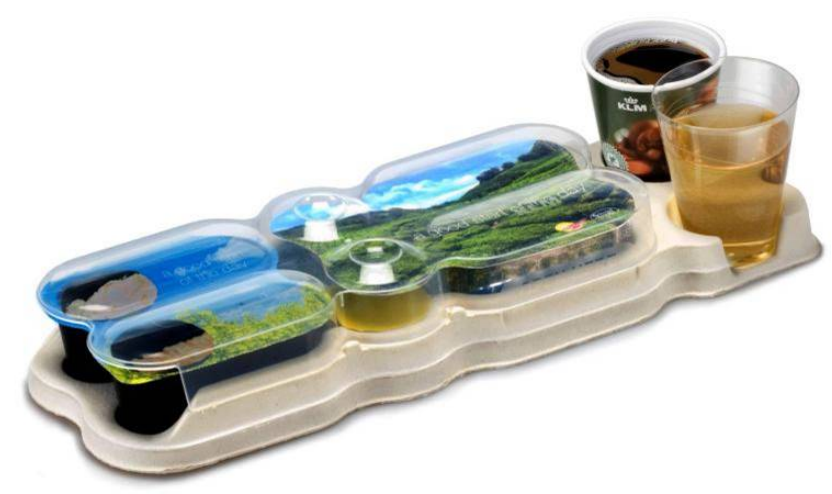

Figure 6. The Morning tapas concept for air travel breakfast

Designed by Pieter Desmet with KVD Amsterdam. Morning Tapas is a breakfast served during intercontinental flights. The food is contained in separate packs, which are in turn covered by an additional transparent plastic lid. Outside of this enclosure are two drinks, one hot and one cold. Passengers first slowly sip the drinks to awaken themselves and their taste buds, before they open the cover. The cover provides extra insulation, so they can take the time without having to worry that their breakfast will turn cold. When opened, the breakfast contains four main food packs: Warm savory (e.g., an omelet); cold savory (e.g., cheeses); warm sweet (e.g., sweet rice); and cold sweet (e.g., fruit yogurt). The smaller cups in the middle contain "condiments" (such as nuts and honey) that can be used to personalize the other meal elements. 


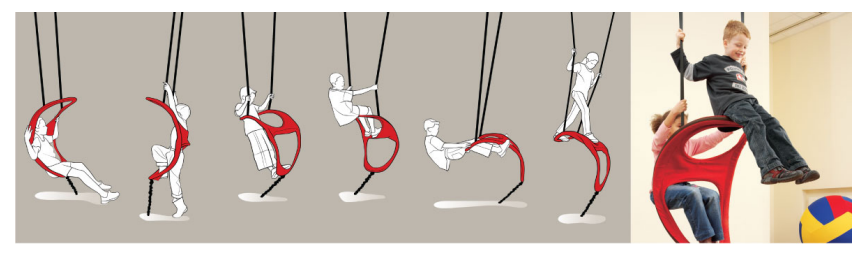

Figure 7. Pogi - design for reversal

Designed by Piem Wirtz, (Janssen-Fritsen). Pogi is a playful object developed for children with AHDD. It can be described as a three-dimensional hoop, which is connected to the floor and the ceiling with elastic straps. The design allows children with an excess of energy to let off steam while they play with it. The design stimulates a transition from brusque and rapid movements (e.g., climbing on top of the device, hanging down from the device), towards more calm and controlled movements (e.g., sitting back in the device). The user can first get rid of energy, and subsequently find a way to calm down.

implicitly understood by a Korean train company, which was dealing with a high number of fare dodgers. There are multiple reasons that might motivate someone to dodge a fare lack of money (telic), thrill seeking (paratelic), opposing authority (negativistic), among others. Nevertheless, the strategy that most public transport companies follow is to emphasize the conforming state: portals, ticket inspectors, message of warning all try to coerce the user to follow the rules. But people who are not sensitive to such stimuli, because they are and remain in another state, will not comply. In a good example of out-of-the-box thinking, the company decided to instead appeal to paratelic motivations. The train ticket doubled as a ticket for a lottery in which all travelers automatically participated when paying for the train. The possibility of winning a lottery is associated with excitement and the paratelic state - thus offering an alternative to the thrill of fare dodging. So instead of enforcing the desired passenger behavior through the conforming state, the company strategy was to change the system in a way that it also appealed to potential fare dodgers who are in the paratelic state (see Tromp et al., 2011).

Design opportunity 3: Products that reverse motivational states. The first opportunity was to use motivational states as a general resource for design creativity. The second was to design products that aim to support the users' current or desired motivational state. The third opportunity is to instead reverse the motivational state of the user. Sometimes it is desirable for people to switch from one state to another - either because the reversal is desired by themselves or by other people - and design can play a constructive role in supporting this switch. A good example is Pogi (Figure 7), a play device intended for use in elementary schools, both indoors and outdoors. The device was designed to support chil- dren in switching from an arousing, playful state to a calm, serious state. The usage scenario is that children who are too aroused or excited to sit still in class are allowed to play for a couple of minutes on Pogi. Pogi supports excited play (see the two rightmost examples in Figure 7). When, due to satiation, the child starts to reverse to a calm state, they will discover that Pogi also supports this calm state (see the leftmost example in Figure 7). User tests showed that this approach proves to be more effective than the conventional approach (forcing the child to sit still) that suppresses rather than reverses their state (for a full description of the project, see Desmet \& Schifferstein, 2011).

The previous section discussed the opportunity to use current motivational states to design for behavioral change. Reversals can also be used to change people's behavior. An example of a design that used motivational reverse to stimulate behavior change in quite a radical way is the "Poor little fish" basin (Figure 8).

By concentrating the negative effects of using too much water completely on a specific, innocent "other", the user will most likely revert from a sympathy-self to the sympathyother state and feel guilty when taking too much water, and feel virtuous (and relieved) when they manage to keep the fish alive. This type of design is conceptual, bordering on being art, and will likely not become a mainstream product

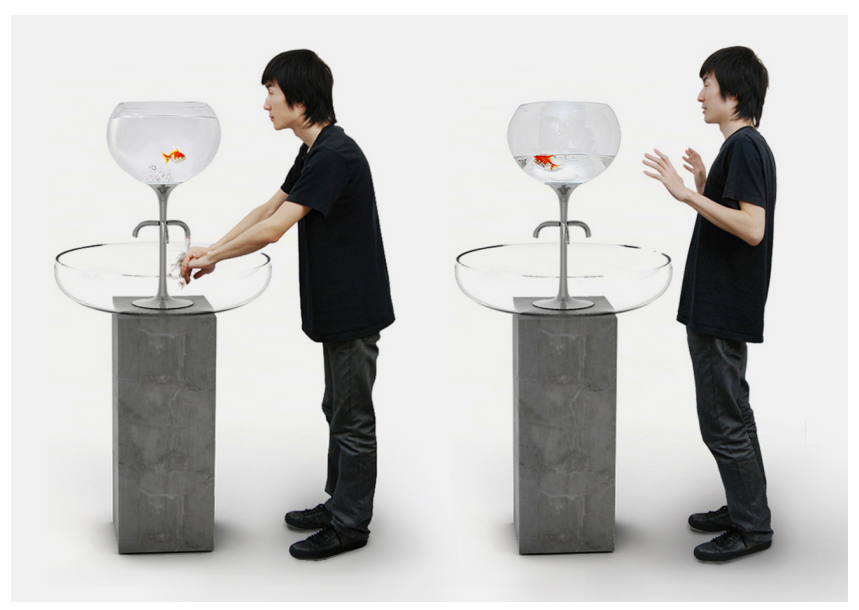

Figure 8. The Poor-Little-Fish wash basin

Designed by Yan Lu. The Poor Little Fish wash basin offers an emotional way to persuade consumers to think about saving water by making consumption tangible. When washing your hands, the water in the fishbowl slowly drains away. This creates the illusion that, if you use too much water, the goldfish will perish. When shut off, the water in the bowl slowly refills. Note that the fish is never in any real danger because, thanks to hidden plumbing in the base of the sink, the water that comes out of the faucet doesn't actually come from the fish tank, nor will it ever drain out completely. 

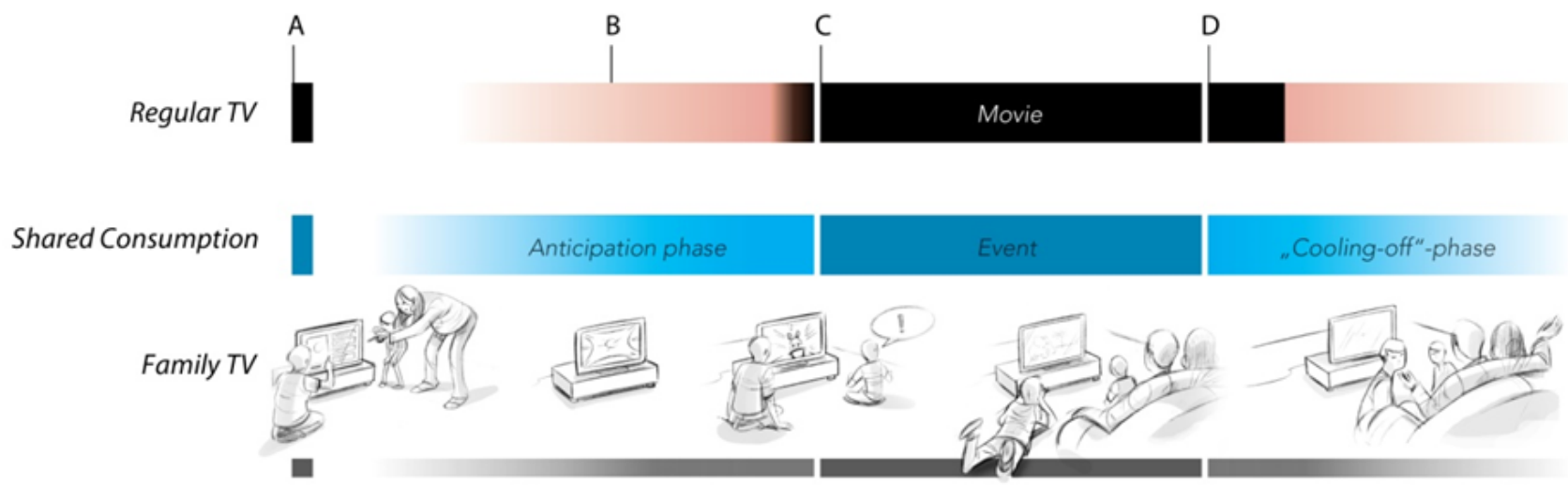

Figure 9. Illustration of the television watching experience over time.

Designed by Hassenzahl, Eckoldt, Diefenbach, Laschke, Lens, E Kim (2013). At the top a typical television experience is depicted, the lower bars show the proposed scenario with the redesigned television. Anticipation stage: the family explicitly commits to watch a program together by making an appointment with the television. The television reminds all participants when the program is about to start. Instead of showing the last part of the preceding program - which would allow for little social interaction - the television displays images and trivia about the upcoming show. Event stage: During the show, the television's in-built camera captures the family members facial expressions. Cooling-off stage: After the show has finished, the television repeats a few of the show's most memorable moments, as well as images of the family's reactions, creating a basis for lively discussion. After a little while, the television dims slowly and then switches itself off.

(not least because of ethical reasons). However, it does show an interesting direction that other designers could implement in more acceptable forms.

Design Opportunity 4: Products that provide variety of experience through psychodiversity. One of the fundamental assertions of reversal theory is that people's motivations are dynamic. Although certain situations are more likely to evoke a certain motivational state than others (contingency), and some people are more likely to be in one state than another (dominance), people experience all motivational states over a longer period of time. Moreover, the theory proposes that people should experience all states regularly - a concept called "psychodiversity" (Apter, 2007b). For an enjoyable experience of extended duration, it seems necessary that products evoke different motivational states over time. This is clear in movies, which can quickly turn from romantic to violent, or from serious to comical, in order to keep the audience engaged. Psychodiversity is a potentially important topic for design of products that are used over a longer period of time, which are becoming more widespread. For instance, many people work all day behind the same computer (office workers), drive in the same vehicle (truck drivers), or use the same kitchen tools (chefs). Similarly, people may watch television or play video games with the same console for several hours of their free time. Designers could use the concept of psychodiversity to make more deliberate considerations of how product experiences should be shaped over time.
An example is the television redesign by Hassenzahl and colleagues (2013). Their intention was to enable a "watching television' activity that is experienced as active family quality time (as opposed to the conventional experience of passivity and social disconnection). In their analysis, they considered a scenario in a completely different context, but which also involves a group of people watching the same thing together: going to see a rock concert with friends. In this experience, there are several enjoyable moments that add to the overall experience. The concert is at a certain predetermined date, so everyone is already eagerly anticipating it in the preceding days. On the night of the concert, the friends meet each other beforehand, and discuss their anticipation for the evening. During the concert the friends stay close and talk to each other once in a while, but most of the time are enjoying the concert. Afterwards, the friends go for a drink, while discussing everything they have seen. This staged experience was subsequently used as a blueprint for the family television experience (Figure 9): What if families would set a date and time to watch their favorite program together, meet half an hour early to anticipate together, have the program gradually begin while they slowly direct their attention towards the television, and take the opportunity to have a nice chat about the show afterwards?

With their concept, Hassenzahl and colleguas (2013), propose new functionality for a television that can support the intended dynamic experience. It could be argued that cur- 
rent televisions are also equipped to allow this kind of usage scenario, however, because they do not actively support it or suggest it, other scenarios are much more likely. The concept of psychodiversity could be helpful in coming up with such longer-term experiences for products. If we look at the example, several state changes could be recognized: Prior to the event, the users make a clear appointment about the date and time of the event, so they can plan around it and rest assured that it will take place (telic/conformist). Just before the event, they build up the anticipation by sharing their expectations (paratelic/allocentric), during the event they are mostly enjoying the program by themselves (paratelic/autocentric), and afterwards, there is time for joint evaluation and laughing about each other's expressions (allocentric), in which the participants can also share their experiences and opinion about the program (mastery). Clearly, the sketched scenario is richer in terms of psychodiversity than a scenario in which different family members turn up at random, watch television as long as they please, and disappear without speaking to others (autocentric). Designers can deliberately consider consecutive events in terms of the different states they evoke, and make sure the experience involves enough variety.

The services industry is another area in which long-term experiences are highly relevant. For example, the "product" that a hotel offers consists of everything that the guest experiences between entering and leaving the hotel - spanning multiple days or even weeks. Similarly, people who choose a reputable airline expect a certain flying experience, which may last up to 24 hours. Such cases are increasingly considered from a design perspective, in a field called "service design". The concept of psychodiversity can add structure to an understanding of what people want in experiences of longer duration.

\section{B: Focus on Opportunities in the Paratelic State}

The four design opportunities of part A focused on how designers can use the diversity of motivational states to research user contexts and design products that better fit people's needs. Part B specifically discusses two opportunities in the paratelic (playful) state. This state is relevant to designers because people who are in this state are focused on the experience and enjoyment activities, rather than on external goals. Evoking and supporting this state enables designers to create more compelling and engaging product experiences. Reversal theory describes two experiential phenomena that are enjoyed by people in the paratelic state: cognitive synergies and parapathic emotions.

Design opportunity 5: Products that communicate and surprise through cognitive synergies.. Cognitive synergies occur when an object, person, or event is perceived to have two qualities simultaneously (or in immediate succession), which seem mutually exclusive (Apter, 2007b). For instance, a child's teddy bear is both a bear (in appearance

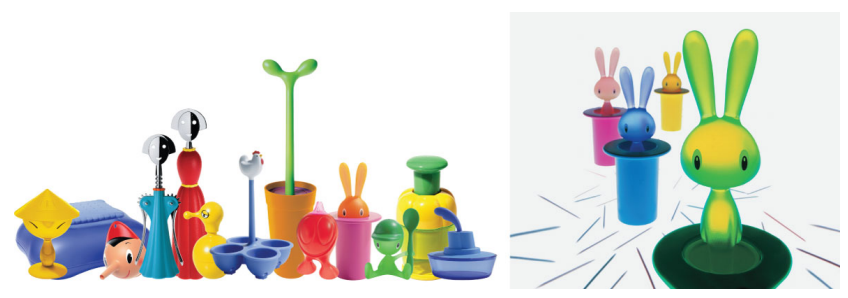

Figure 10. Cognitive synergy in Alessi products (images courtesy of Alessi S.p.A.)

and identity) and not a bear (in reality). A painting is both a three-dimensional landscape and a piece of canvas with paints. When people encounter (new) cognitive synergies, they can create powerful reactions, provided people are in the right mood for them (the paratelic state). Not all synergies will automatically provoke such a reaction - some have become so ubiquitous (e.g., teddy bears and paintings) that this effect does not play a significant role anymore (Apter, this issue).

Because the use of synergy is not commonplace in functional products, designers have an opportunity to make use of its powerful effect to enrich user experiences. In the 1990s, the Italian household utensil company Alessi (Alessi, n.d.) acquired fame by producing idiosyncratic families of household products such as graters, kettles and toothbrushes with unusual shapes. These products, often involving animals, cartoonish characters, and bright colors, seem to be making use of cognitive synergies (Figure 10).

A typical example of an Alessi product that uses cognitive synergy is the Magic Bunny, a toothpick holder that includes a bunny, which has to be pulled from the hat to get to the toothpicks (Figure 10, right). The Magic Bunny involves two kinds of synergies. The first and most obvious synergy is that the product is a bunny-in-a-hat, and at the same time it is neither a real bunny nor a real hat. Simultaneously, a second, more affective synergy seems to occur between the product as a serious and a playful object. Toothpick holders are generally serious products for adults, catering to telic needs. At the same time, the appearance and interaction of the toothpick holder is quite playful - even childlike.

Product synergies have also been studied by design researchers. For example, Ludden and colleagues (2008) systematically studied how products can evoke surprise. She found that designers can juxtapose non-congruous visual and tactual attributes to create a surprising synergy. This kind of synergy can be observed in many of the products that people find fascinating or surprising. For instance, a material can look like it is soft and flexible, like cloth, but when touched, feel hard and heavy. The lamp "Konko" uses this illusion (Figure 11, left). Alternatively, a product can be made out of a material that hides another material. The chair "Bastian" looks surprisingly like it is made of paper, which would 

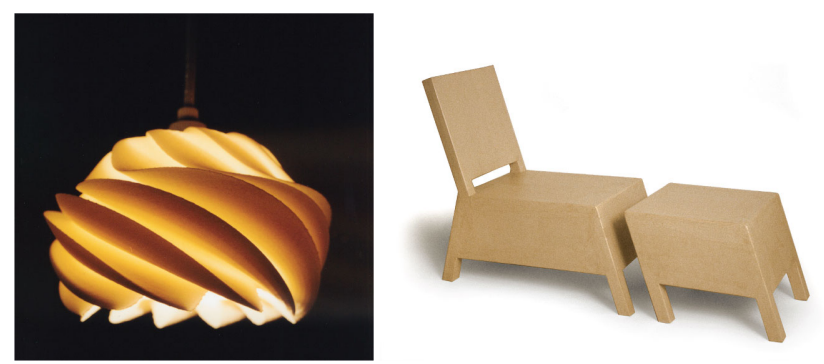

Figure 11. Konko lamp and Bastian chair

make it unfit to support the weight of a person, but directly underneath the paper there is wood, which gives the chair its rigidity (Figure 11, right).

Besides amusing, attracting and delighting the user, cognitive synergies can also be used to convey a message about the product, if they are used in the form of a metaphor. Cila et al. (2014) explored how designers can make use of visual metaphors in design. Visual metaphors, like verbal metaphors, carry messages - they are used to convey something about the object of metaphor. For example, the sentence "Life's a journey" conveys the idea that the life has journey-like attributes, such as hurdles and a destination. Similarly, products can use visual metaphors to express something about themselves. For example, the product "USB padlock" by Ina Jade Seng is a USB storage drive that emphasizes safety by resembling a padlock (Figure 12, left). By reminding people of a padlock, it emphasizes that it has padlock-like attributes (i.e. being very resistant against data theft). With a similar strategy, "Trea", an outdoor portable stove by Michael Kononsky, summons images of naturalness by resembling a campfire made of branches (Figure 12, middle). Lastly, the bottle of the perfume "Flowerbomb" by Victor and Rolf resembles a hand grenade to attest to the powerful effect of its contents (Figure 12, right). Designers can explicitly look for such a "play-on-images" to both delight and convince the user of a certain quality of the product.

Design Opportunity 6: Products that offer emotionally rich experiences through parapathic emotions.. Many psychological theories explicitly or implicitly promote the idea that emotions can be neatly divided into positive emotions (e.g., joy, hope, admiration) and negative emotions (e.g., fear, anger, sadness). However, such theories run into trouble when trying to explain why people actively seek out activities that are expected to evoke negative emotions, such as parachute jumping (fear), reading tabloids (indignation), stopping to see a car accident (dismay/horror), or watching a tearjerker movie (sadness) (e.g., see Fokkinga \& Desmet, 2012). Reversal theory proposes that negative emotions have pleasant counterparts - "parapathic emotions" - which are experienced in the paratelic state (Apter, 2007b). "Rich experience design", a subfield of experience design, studies para- pathic emotions, and looks for ways to apply these to products. Eliciting such emotions through products is an interesting opportunity for two reasons. First of all, they broaden the palette of possibly interesting experiences that designers can evoke through design. Variety is one of the most important aspects of engaging experiences (see also design opportunity 4). Secondly, parapathic emotions inherently involve a pleasant high arousal and are as such among the most engaging and memorable emotional experiences that people can have. The theory puts forth that parapathic emotions are experienced under the influence of a protective frame, of which there are three: the detachment frame, the safety-zone frame, and the confidence frame (Apter, 2007a). Protective frames are psychological constructs, which also means that their occurrence is partly determined by personal differences. Nevertheless, products can play a role in the formation of protective frames that ranges from supportive to determinative. For example, the equipment of the mountain climber supports her protective frame while climbing, but she also needs to rely on her skills and climbing partner to be able to enjoy the experience. In contrast, a solid railing in front of a cliff in a tourist area will provide a protective frame to all but the most squeamish. The following sections discuss strategies that a designer can use to support the construction of each of the three protective frames, and give examples of product concepts that have been created with these strategies.

The detachment frame. The detachment frame occurs when people experience thrill and danger as an observer, such as when people watch fictional characters get into trouble in movies. People believe that they themselves are not in any danger, yet they also feel as if they were. This creates the enjoyable emotional experience that is partly the reason that movies about arousing topics like alien invasions, natural disasters, and supernatural horror are so popular. This does not hold true for everyone, though. For instance, some people find horror movies genuinely scary - for them, the detachment frame of the movie screen is not strong enough (Andrade \& Cohen, 2007).

Evidently, when designing for the formation of a detachment frame, the source of arousal should be represented and

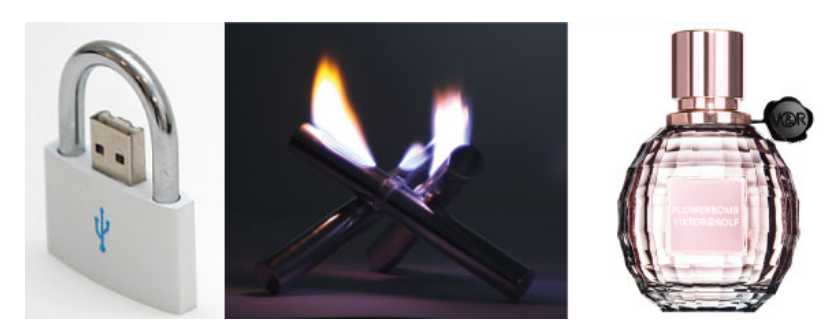

Figure 12. A USB storage drive (image by Roy Hessing), an outdoor portable stove, and a perfume bottle (image by Douglas.nl), all representing visual metaphors of different kinds. 
not actually present or real. The product is in that case most likely the medium of this representation. This is clear in a product concept that was developed to evoke parapathic fear emotions: the "Run for your life-wristband" (Fokkinga \& Desmet, 2014). The wristband is meant for runners who do not always feel engaged by the running experience and, as a result, unmotivated to run as often as they would like. The wristband intends to add excitement by giving the runner the experience of being chased (Figure 13). It does this through sound (headphone), visual (display), and tactile input (vibration). The wristband was developed as a platform that could run different programs and outputs. For example, the user could be chased by sounds of wild dogs, by a voice, or by abstract beeps. Similarly, there were different options for the display that showed how close the pursuer was at any given moment: for example, a number display that showed the distance in meters, or a ball that gave off a gentle light when the pursuer was close, which turned to a pulsing red light when the pursuer came close. Both the sounds and the display represented the pursuer, but for some people it felt quite real. The test of the concept showed that more than half of the participants enjoyed the running with the prototype and felt more motivated to run. The participants who did not enjoy it, fell into two groups. Some found the device too frightening, or it made them too nervous while running. It seemed that for these participants, the detachment frame was not strong enough. Others were not very impressed by the prototype, and mostly ignored it during the run - for them, the prototype failed to evoke arousal. Another important conclusion was that different combinations of outputs (visual, audio) had different effects on the runners. For instance, the dog sounds combined with the colored light ball evoked the strongest emotions, and had the strongest effects on running motivation (Fokkinga \& Desmet, 2014). This shows that designers that aim to evoke rich user experiences should consider psychological effects beyond the conceptual level, to understand how to design the specific (material) manifestations of the product.

The safety-zone frame. The safety-zone frame occurs in a situation in which threats are real, but seem to be at
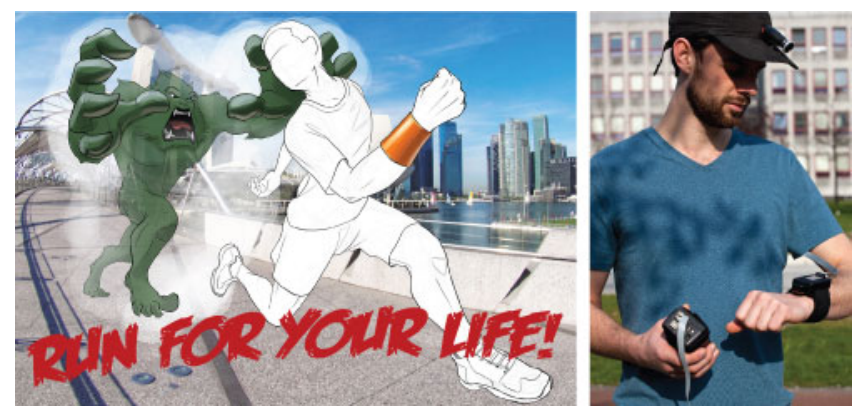

Figure 13. The "Run for your Life" concept and prototype

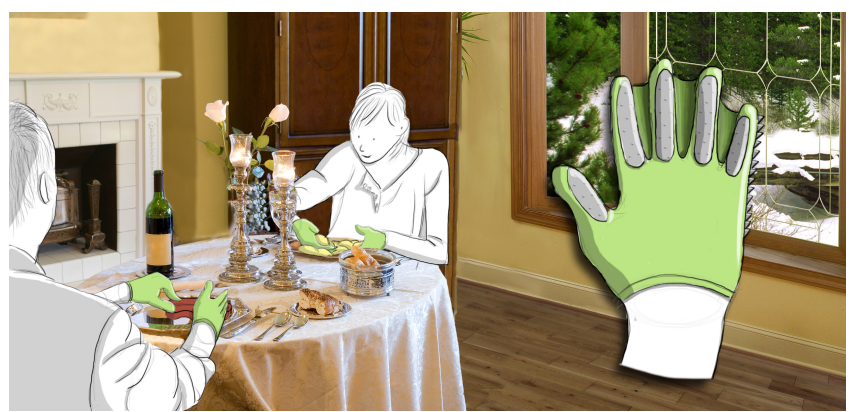

Figure 14. The dinner glove concept

a safe distance. An example of a concept that makes use of the safety-zone frame is the "Dinner glove" (Fokkinga \& Desmet, 2013). The product is intended to let people enjoy the negativistic state in a restaurant context. Restaurants are associated with many rules, and sometimes people even feel anxious about accidentally breaking one of them. The dinner glove is a product that lets people intentionally break a restaurant etiquette: to eat with your hands.

The glove is made of silicon and users can wear it to eat with their hands in a hygienic way (Figure 14). This tool is intended as a complete replacement for standard cutlery. The outside of the fourth finger is serrated and sharp to afford cutting, and the fingers are webbed to easily scoop up soups. The intention of the product is to let people break a rule, but in a safe and hygienic way. In this situation, the restaurant also takes part in creating the safety-zone. The guests understand that the restaurant is a place where this type of eating is allowed. If someone were to bring the glove to a regular fancy restaurant, they would likely also feel genuine embarrassment. Conversely, if there would be a protective frame but no arousal, the product would also be unsuccessful. For instance, if this product would be introduced in a restaurant where it is already common that people eat with their hands (like a fast food restaurant), there would not be any arousal involved in the use of the product.

The confidence frame. Confidence is a psychological state that cannot be directly evoked by design. However, confidence can be supported by products. A driver derives part of her confidence in dealing with traffic dangers from the responsive controls of her car, and a smartphone user can enjoy getting "lost" in a strange city, because he can always fall back on the maps app of his phone to redirect him. This shows that products can essentially support confidence in two ways: by increasing the amount of control the user has over the situation, and by increasing the amount of information a user has to solve a problem. Both are illustrated in a study by Yoon et al. (2012), who researched how much interest people experienced towards different types of music players. The music players were prototypes developed by the researchers and looked or worked nothing like conventional music play- 
ers (see Figure 15). The two music players were identical in appearance, but differed in how easy they were to understand and to physically control. One prototype was easier to figure out and control, while the other was more difficult in both regards. The idea behind the study was to see to what extent people enjoy novelty in products, when they are confronted with different levels of difficulty to explore that novelty. Exploring novel things raises arousal, which is pleasant in the paratelic state but unpleasant in the telic state. People who are in a goal-oriented (telic) state would not be interested in exploring a music player and would just want to know how they can get it to play music without frills. The withinsubjects experiment revealed that people only enjoyed the novelty of the first music player, which they could understand and control, but not the second music player, which was equally novel but harder to understand and control. In terms of reversal theory, the arousal from exploring unknown music players was only enjoyable when people felt confident about their ability to control it. This was an important finding, because some people in the design (research) community believed that novelty would always be experienced as a negative feature for functional products (e.g., Mahlke, Minge, \& Thüring, 2006).

\section{Discussion}

In this paper, we proposed six design opportunities that are inspired and facilitated by reversal theory. Design focuses on the needs or goals of users: good design enables the user to fulfill their goals, with "efficiency" as an important indicator of quality. A reversal theory perspective shows that other indicators apply as well and that it depends on the user's motivational state what indicator is relevant. Whereas efficiency and predictability are relevant for those who are in a telic state, they can be irrelevant for those who are in a paratelic state - in that state, people look for challenge and surprise. While, at first sight, the basic telic-paratelic distinction may seem somewhat obvious, the interesting aspect of this and the other motivational pairs is that (in most cases) users cannot be characterized as being either in one or the other state:

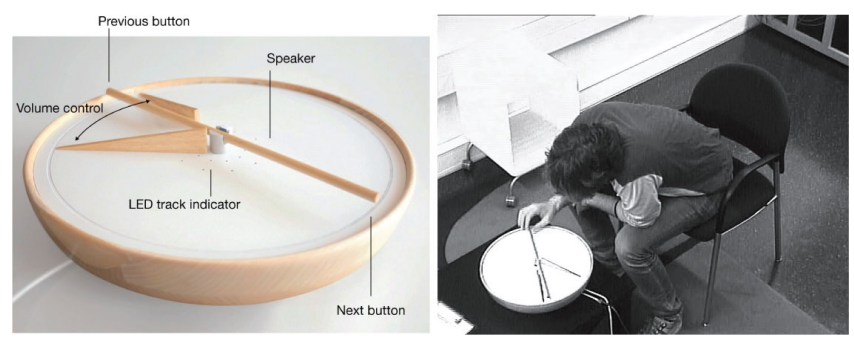

Figure 15. The music player as it was used in the experiment. The two versions of the music player were the same physical device, but differed in their programming. people reverse from one to another. Design that facilitates reversals in a way that is recognizable by the user can be both novel and appealing, as shown by the Hush Pod chair in Figure 4. Moreover, the four motivational state pairs offer nuanced and rich design opportunities because motivations can be understood as combinations of states. For example, it may be straightforward to design for 'mastery' but it becomes more challenging and therefore interesting to design for 'mastery-alloic.' Our intention with the first four design opportunities was to dose nuance and complexity. The first opportunity is to use the motivational states as a basic source of inspiration, the second requires an understanding of the motivational states of the users in the context of use, and the third adds the challenge of reversing the users' motivational state. The fourth is the most challenging because it proposes to design for psychodiversity, which requires an understanding of design as a product-service combination, including the dynamics of all usage stages. The fifth and sixth opportunities illustrate that principles from reversal theory can also be used to design for unconventional pleasurable experiences, like the 'pleasurable embarrassment' facilitated by the Dinner Glove in Figure 14.

Our aim was to make use of two key contributions of reversal theory to the designers' understanding of human behavior and experience: it offers a dynamic rather than static and a holistic rather than fragmented model of human functioning. To respect these contributions, we decided to formulate general opportunities that integrate theoretical insights rather than to discuss these insights separately. The drawback of this approach may be that it is not precisely clear how the opportunities are distinct from each other and where they show overlap. Even so, we hope that they each provide useful points of entry into the theory, fuelled by realistic design challenges. These six opportunities may not be exhaustive - more could probably be formulated. Nevertheless, we hope that they inspire reversal theorists to explore how the multi-faceted experiences in human-product relationship can be best understood within reversal theory.

Several topics remain to be explored by future research and design work. For instance, as experiences-over-time are becoming increasingly important in the design of products and services, the concept of psychodiversity could be a key concept to structure these experiences. However, only a little research has been done to apply and evaluate such an approach in design. For example, would it be possible, and desirable, to cover all motivational states within a product experience? Are certain motivational states more logical or desirable to follow from each other? Or would it always depend on the context of use? Secondly, more research could point out how the different design opportunities relate to each other. It seems for example in certain cases more beneficial that a product makes use of the current motivational state of the user - like the Korean train ticket system - while at other 
times it is more beneficial to try to bring about a reversal in the user - such as the Poor-little-fish example. Developing a set of guidelines could help designers to determine which opportunity works best for a given design problem. Thirdly, it is interesting to understand how designers can use reversal theory in combination with other psychological theories. As discussed in the introduction, the last few decades have seen a large increase in the use of psychological theory in design and a successful integration of insights from different theories and models would further help designers to holistically create relevant and enjoyable products.

We also hope that these six design opportunities inspire designers and researchers to invest more time in studying the theory and to discover their own useful insights. We are certain that their design activities will benefit from the rich understanding of human motivation, experience, and behavior that is offered by reversal theory.

\section{References}

Alessi. (n.d.). Alessi: Italian Design Factory - Alessi products. Retrieved 4 July 2014, from http://www.alessi.com/en/

Andrade, E. B., \& Cohen, J. B. (2007). On the consumption of negative feelings. Journal of Consumer Research, 34(3), 283-300.

Apter, M. J. (2007a). Danger: Our quest for excitement: Oneworld Publications Ltd.

Apter, M. J. (2007b). Reversal theory: the dynamics of motivation, emotion, and personality (2nd ed.). Oxford: Oneworld.

Charity Miles. (n.d.). Retrieved 18 April, 2104, from http://www.charitymiles.org/

Cila, N., Hekkert, P., \& Visch, V. (2014). Source selection in product metaphor generation: The effects of salience and relatedness. International Journal of Design, 8(1), 15-28.

Desmet, P. M. A. (2012). Faces of product pleasure: 25 positive emotions in human-product interactions. International Journal of Design, 6(2), 1-29.

Desmet, P. M. A., \& Schifferstein, H. N. J. (2011). From floating wheelchairs to mobile car parks: A collection of 35 experience-driven design projects. The Hague. The Netherlands: Eleven International Publishers.

Desmet, P. M. A., \& Schifferstein, H. N. J. (2012). Emotion research as input for product design. In J. H. Beckley, D. Paredes \& K. Lopetcharat (Eds.), Product innovation toolbox: A field guide to consumer understanding and research (pp. 149-175): John Wiley \& Sons.

Digman, J. M. (1990). Personality structure: Emergence of the five-factor model. Annual review of psychology, 41(1), 417-440.

Fogg, B. (2009). A behavior model for persuasive design. Paper presented at the Proceedings of the 4th international conference on persuasive technology.
Fokkinga, S. F., \& Desmet, P. M. A. (2012). Darker Shades of Joy: The Role of Negative Emotion in Rich Product Experiences. Design Issues, 28(4), 42-56.

Fokkinga, S. F., \& Desmet, P. M. A. (2013). Ten ways to design for disgust, anxiety, and other enjoyments. International Journal of Design, 7(1).

Fokkinga, S. F., \& Desmet, P. M. A. (2014). Run for your life! Using emotion theory in designing for concrete product interactions. Paper presented at the 9th International conference on Design and Emotion, Bogota, Colombia.

Ford, M. E. (1992). Motivating humans: Goals, emotions, and personal agency beliefs: Sage Publications.

Hassenzahl, M., Eckoldt, K., Diefenbach, S., Laschke, M., Lenz, E., \& Kim, J. (2013). Designing moments of meaning and pleasure. Experience design and happiness. International Journal of Design, 7(3), 21-31.

Heskett, J. (1980). Industrial design: Thames and Hudson London.

Hofstede, G., \& Hofstede, G. J. (2005). Cultures and Organizations: Software of the Mind. New York, NY: McGrawHill.

Ludden, G. D., Schifferstein, H. N., \& Hekkert, P. (2008). Surprise as a design strategy. Design Issues, 24(2), 28-38.

Mahlke, S., Minge, M., \& Thüring, M. (2006). Measuring multiple components of emotions in interactive contexts. Paper presented at the CHI'06 extended abstracts on $\mathrm{Hu}-$ man factors in computing systems.

Maslow, A. H. (1943). A theory of human motivation. Psychological Review, 50(4), 370.

Mehrabian, A. (1995). Framework for a comprehensive description and measurement of emotional states. Genetic, social, and general psychology monographs.

Miaskiewicz, T., \& Kozar, K. A. (2011). Personas and usercentered design: how can personas benefit product design processes? Design Studies, 32(5), 417-430.

Mullet, E., Kpanake, L., Zounon, O., Guedj, M., \& Sastre, M. T. M. (2014). Putting Reversal Theory's Model of Four Domains of Experience in the Hot Seat. Journal of Motivation, Emotion, and Personality, 2(1), 1-9.

Ozkaramanli, D., Fokkinga, S. F., Desmet, P. M. A., Balkan, E., \& George, E. (2013, 17-19 November, 2013). Recreating AlaTurca; consumer goal conflicts as a creative driver for innovation. Paper presented at the Brilliant Transformations; proceedings of Qualitative Research 2013, Valencia, Spain.

Philips. (n.d.). Philips Wake-up light. Retrieved 10 July 2014, from http://www.usa.philips.com/cp/HF3470_60/wake-up-light

Roozenburg, N. F., \& Eekels, J. (1995). Product design: fundamentals and methods (Vol. 2): Wiley Chichester.

Sanders, E. B.-N., \& Stappers, P. J. (2008). Co-creation and the new landscapes of design. Co-design, 4(1), 5-18. 
Schwartz, S. H. (1994). Are there universal aspects in the structure and contents of human values? Journal of social issues, 50(4), 19-45.

Senz. (n.d.). Senz Umbrellas. Retrieved 10 July 2014, from http://www.senzumbrellas.com/

Sheldon, K., Elliot, A., \& Kim, Y. (2001). What is satisfying about satisfying events? Testing 10 candidate psychological needs. Journal of personality and social, 80, 325-339. doi: 10.1037//O022-3514.80.2.325

Tromp, N., Hekkert, P., \& Verbeek, P.-P. (2011). Design for Socially Responsible Behaviour: A Classification of Influence Based on Intended User Experience. Design Issues, $1-25$.
Van Boeijen, A. G. C., Daalhuizen, J. J., Zijlstra, J. J. M., \& Van Der Schoor, R. S. A. (2013). Delft Design Guide. Amsterdam: BIS publishers.

Vestergaard. (n.d.). LifeStraw water filters. Retrieved 10 July 2014, from http://www.vestergaard.com/ourproducts/lifestraw

Visser, F. S., Stappers, P. J., Van der Lugt, R., \& Sanders, E. B. (2005). Contextmapping: experiences from practice. Codesign, 1(2), 119-149.

Yoon, J., Desmet, P. M. A., \& van der Helm, A. (2012). Design for Interest: Exploratory Study on a Distinct Positive Emotion in Human-Product Interaction. International Journal of Design, 6(2). 